\title{
How Consumers' Attitudes towards Alternative Food Network Affect Their Consumption Satisfaction - Empirical Evidence from Zhengzhou
}

\author{
Bo YANG, Meng-Ting LIU, Guo YU*
}

\begin{abstract}
With the continuous development of economic globalization and the increasingly diversified food culture of people, food hygiene and safety have become hot topics that have attracted much attention. The continuous occurrence of vicious food safety accidents has caused people to pay great attention to food safety. It is necessary to re-examine the issue that has risen to the height of national public safety, and it is necessary to increase the supervision of food safety. Based on 280 valid questionnaire data of alternative food network (AFN) in Zhengzhou, using structural equation model, this study investigates how consumers' attitudes towards AFN affect their consumption satisfaction. The results show that: the attitude towards AFN has a direct positive impact on consumer satisfaction, and indirectly affects satisfaction by affecting the perceived quality of consumers, and has an indirect positive impact on satisfaction through influencing the participation of AFN activities. The policy implications are: implement participatory security system, learn from the commercialization of mainstream food network, pay more attention to the quality of products, pay more attention to the needs of consumers and establish a "food community".
\end{abstract}

Keywords: alternative food network; consumption satisfaction; perceived quality; structural equation model

\section{INTRODUCTION}

After the industrial revolution, industrialized production and circulation in the field of agricultural food brings about increasingly serious environmental, economic, and social problems, such as environmental pollution, massive carbon emission, food safety crisis, marginalization of smallholders and difficulties in maintaining smallholders' livelihoods, etc. The advocacy and sporadic practice of alternative food network aims at localization and green. At that time, a group of middleincome people concerned about environmental protection, food safety and the survival of smallholders spontaneously organized and cooperated with local smallholders, which created some new production and circulation organizations and modes of green products, such as community supported agriculture (CSA) farm and farmers' market. This was obviously different from the mainstream food network of long-distance, large-scale transportation and commercialization. The framework analysis of Polanyi et al. [1] of mainstream market network is often used to explain the form of AFN. He believes that if a single market mechanism is allowed to influence the destiny of mankind, society will fall apart. Therefore, the mainstream market mechanism will give birth to the corresponding confrontational social movements. AFN is one of these social movements. In China, the representative view is that the rise of middle-income groups and frequent food safety incidents lead to the emergence of community supported agriculture and farmers' market in big cities, which is a kind of self-organization of consumers and producers' joint self-help [2].

From the development practice of AFN, some middleincome groups that pay attention to environmental protection and food safety actively promote the production of AFN and purchase products from it when they are disappointed with the mainstream food network. However, even in countries where AFN appears earlier, such as the United States, the size of AFN is very small compared with the mainstream food network. According to the statistics from the United States Department of Agriculture, the total income of alternative food network, including CSA, farm picking, and farmers' market, only accounts for $0.4 \%$ of the total farm income of the country (USDA, 2009). Most of the agricultural products still enter into a vertical marketing system and eventually link to the mainstream food network. For example, only $1 \%$ of the agricultural products produced in the Santa Barbara region of California, the main agricultural producing area of the United States, remain locally. This shows that the mainstream food network has a strong marketing capacity, which may be the optimal choice in terms of economic efficiency, but only if social and environmental costs are not taken into consideration.

A question needs an answer. The attitude of these middle-income groups disappointed by the mainstream food network affects their consumption satisfaction after joining AFN. The reason why this question is important is that in practice, these middle-income groups pay more attention to environmental protection, and agree with the main concept of AFN. Answering this question helps to study the consumption law of this minority group, provides theoretical basis for expanding the scale of AFN consumers, and theoretically helps to enrich the research on green consumer behavior. This study attempts to answer this question based on the current situation and data of China.

In 2008, China's first CSA farm "Little Donkey Farm" was set up in Beijing, and CSA farms have sprung up in the suburbs, surrounding areas of large and medium-sized cities since then in China. In 2015, organic farmers' market began to appear in big cities such as Beijing, Shanghai and Guangzhou, and was welcomed by middle-income groups. According to incomplete statistics, by the end of 2017 , there had been more than 300 community supported agricultural farms in China, and more than a dozen of ecological farmers' markets were scattered in several major cities [3]. With the practice and scale expansion of AFN in China, the corresponding research also appears and increases. According to the existing literature, the following study has been carried out around the topics related to this study: (1) the main characteristics of AFN. AFN connects producers and consumers directly, and reembeds the de-embedded food market into the social system [4]. The core characteristics of AFN are localization and environmental protection [5]. AFN can improve the social and economic equity, while the mainstream food network leads to the increase of social 
and economic inequality [6]. In $\mathrm{AFN}$, the network interaction between consumers and producers creates a "tactile space" and forms a food community [7]. (2) Why are consumers willing to purchase green products from AFN? Empirical studies show that the main motivations for consumers to purchase from AFN are to obtain green food, fresh food, support local agricultural production, and experience the production process [8]. The main purpose of China's consumers is individually utilitarian, obtaining green and safe agricultural products, without considering the social functions such as experiencing the production process, supporting local small and medium-sized farms, and cultivating their own environmental awareness [9]. What is particularly noteworthy is that, unlike consumers in the western countries, Chinese consumers have low trust in the green business certification system [10], which is one of the main reasons why consumers are willing to purchase green products from AFN. (3) How to build consumers' trust in AFN. In AFN, open production mode, shared thirdparty relationship, caring concept, frequent interaction with consumers and providing high-quality products are effective methods to build consumers' trust [11]. In the process of trust building, consumers' social media participation can play a positive role [12]. In China, participatory certification at the exploratory stage is an important means and safeguard measure for the construction of trust mechanism [13]. AFN is highly integrated with the Internet in China, and the Internet plays a positive role in the establishment of trust relationship [14]. In the future development of AFN in China, the "institutional trust" based on laws and regulations needs to pay attention [15]. (4) How the customer satisfaction is affected in AFN. Less variety of products and inconvenient transportation have a negative effect on consumer satisfaction [16]. Picking activities can improve consumers' utility, while storage activities bring negative effects [17]. Deep interaction between producers and consumers can significantly improve consumer satisfaction [7]. Both the quality of products observed by consumers and their attitudes towards AFN can affect their satisfaction [18]. In terms of products, the product attributes that affect consumer satisfaction are: quality control, health status, variety diversity, purchase convenience and taste. In terms of services, they are: delivery of products within the promised time, timely notification of rights and interests' changes, attitude and ability to solve problems, sense of security in the transaction process, and whether farm personnel have sufficient professional knowledge [10].

Existing literature provides a wealth of materials for this study. At the same time, it can be seen that there is no direct research on how attitude affects satisfaction in AFN. This study attempts to carry out research in this area.

\section{DEFINITION OF CONCEPTS}

For the discussion of consumer satisfaction in AFN, this study analyzes it with four concepts: satisfaction, perceived quality, attitude towards AFN, and participation in AFN activities. In order to describe the path of influence, the structural equation model is used.

\subsection{Satisfaction}

Satisfaction reflects the consumer's evaluation of a certain product or a certain service, and is a reflection of the utility of consumer activities [19]. In AFN, it reflects the overall recognition of AFN by consumers, including both the purchase and post purchase experience. There is a close and direct relationship between satisfaction and purchase behavior: the improvement of satisfaction will prompt consumers to buy the product again [20]. Satisfaction is not directly related to purchase behavior. Green product is a kind of trust product, in which trust plays a key role. In addition, the switching cost of consumers in different purchasing channels and the lack of attractive alternatives also affect the correlation between consumers' purchase degree and purchase behavior [21].

\subsection{Perceived Quality}

When choosing a product, consumers will evaluate its quality comprehensively according to its intrinsic and extrinsic characteristics, which is both objective and subjective. In AFN, the extrinsic attributes of products mainly include physical characteristics, such as color, taste, freshness, etc. Intrinsic attributes include price, place of origin, etc. Economic theory divides commodities into search goods, experience goods and trust goods. The quality of search products can be judged by consumers before purchase and the quality of experience products can only be judged after consumption. However, it is difficult to judge the quality of trust products even after consumption. Green product is a kind of trust product [22]. Compared with the consumers in the mainstream food network, consumers in AFN pay more attention to whether the food is green or not and whether it is produced locally. The "perceived quality" in this study is represented by several indications closely related to the purchase behavior of consumers in AFN, referring to the method of Hansen [23].

\subsection{Attitude towards AFN}

Consumers' attitudes towards a certain kind of goods can directly affect their willingness to purchase the goods, and it is one of the leading indications to predict their purchase behavior [24]. In the field of consumer behavior research, attitude represents a positive or negative view of a consumer before purchase, including personal feelings, intentions, and trust. A large number of empirical studies show that there is a positive correlation between attitude and purchase intention. In the consumption of green products, attitude is the intermediary variable between purchase behavior and demands of health and environmental protection. This study uses the methods of Archer et al. [25] for reference, and uses some survey indications to reflect consumers' attitudes towards alternative food network.

\subsection{Participation in AFN Activities}

AFN has an obvious characteristic, that is, it pays more attention to the interaction between producers and consumers, and attaches more importance to guiding consumers to experience the production process. Taking community supported agriculture as an example, producers will invite consumers to the farm to experience the production or picking process, and hold some parent-child 
activities. In the farmers' market, the producers will produce food on site or invite consumers to participate in food production. In the network space of AFN, consumers and producers also interact more frequently, forming a "tactile space" on the network. In the mainstream food network, consumers have no idea where the products they buy come from, what the production process is, and who produces them. AFN can let consumers know clearly where the food they purchase comes from, who produces it, how it is produced, and even who participates in the production and circulation links through various communication and interaction activities.

\section{THEORETICAL FRAMEWORK}

This study attempts to construct a theoretical model to analyze the relationship between the above four latent variables, and discuss how the attitude towards AFN affects consumption satisfaction, as shown in Fig. 1.

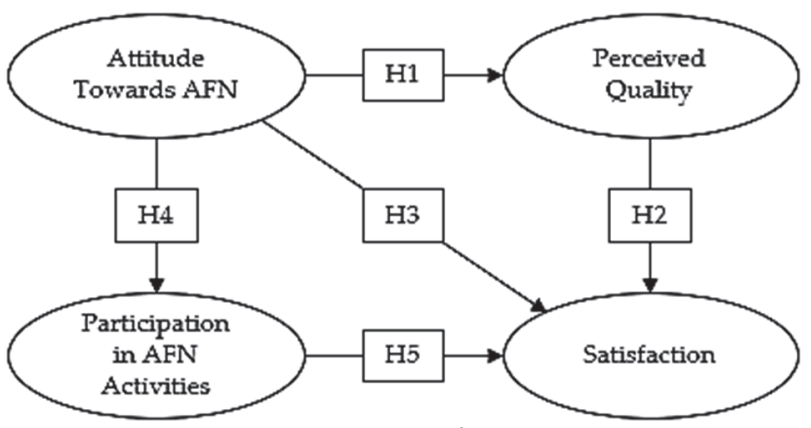

Figure 1 Theoretical framework

H1: Consumers' attitudes towards AFN have a positive impact on their perceived quality. Consumers' personal characteristics, cultural and social background can affect their judgment of product quality before purchase [26]. This is more obvious in the consumer groups who pay more attention to environmental and ethical factors, such as green product consumers [27]. H1 hypothesis will be used to test whether consumers' attitudes have a positive impact on perceived quality in the alternative food network as expected, and estimate the impact through empirical analysis.

H2: Consumers' perceived quality of AFN products has an important impact on their satisfaction. A large number of studies have shown that consumers' perceived quality of products directly affects their consumption satisfaction [28]. According to the existing literature, this effect is positive and significant.

H3: Consumers' attitudes towards AFN significantly affect their satisfaction. Consumers' evaluation of products is a very complex process, which is neither objective nor rational. In the evaluation of trust products, consumers are easy to be influenced by their personal beliefs and have strong preconceived subjectivity. Based on this, the hypothesis is put forward.

H4: Consumers' attitudes towards AFN have a positive impact on their participation in AFN activities. An important difference between AFN and mainstream food network is that there are more communication activities online and offline, between producers and consumers, and among consumers in AFN than in mainstream food network. If consumers hold a positive attitude towards
AFN, they will recognize the cultural values of alternative food network and actively participate in the related activities. Otherwise, they will only take AFN as a channel to purchase green products.

H5: Consumers' participation in AFN activities has an important impact on their satisfaction. Participation in AFN activities will enable consumers to have a deeper understanding of where the products come from, who makes them, what the production process is, how green production process can protect the environment. These can have an impact on the evaluation of consumers, and then affect the consumer satisfaction.

\section{DATA AND RESEARCH METHODS 4.1 Data Collection}

In order to understand the situation of AFN in Zhengzhou, the consumers in this sample come from both farmers' market and community supported agriculture. Because of the small scale of AFN consumers in Zhengzhou, this study does not adopt the method of probability sampling. From October to November of 2019, 356 consumers were surveyed, and 328 questionnaires were collected. After excluding the invalid questionnaires, which were incomplete, whose answers were mostly extreme or all the same, 280 valid questionnaires were left, and the effective recollection rate was $78.7 \%$. Among them, 191 were community supported agricultural consumers and 89 were farmers' market consumers. Since the authors are both consumers of community supported agriculture and farmers' market, all the surveys are directly related.

\subsubsection{Community Supported Agriculture}

The consumers come from farm A and farm B in Zhengzhou. The two farms are located in the suburb of Zhengzhou. Farm A covers an area of about $90 \mathrm{mu}$. It has been engaged in ecological agriculture for nearly seven years. It mainly grows vegetables and a small amount of staple food, and breeds pigs, sheep, geese, chickens, fish, etc. Nearly 200 consumers are regular customers. Farm B has been engaged in ecological agriculture for four years, only growing vegetables, covering an area of about $50 \mathrm{mu}$. The operating methods of these two farms are the same, in which consumers pay a certain amount of money in advance each year, from which to deduct when purchasing products. Only the seasonal vegetables are planted, and the vegetables are delivered once or twice a week and sent to the consumer's home by the farmer or the express. Both farms have WeChat groups, in which the production process and weekly product list will be sent to the consumers. There is comprehensive communication and active interaction between consumers and producers, and among consumers about green food, environmental protection and so on. Both farms also have experience activities. They will organize consumers to participate in production and farmhouse activities from time to time. Frequently interactive communication communities are formed both offline and online, forming online and offline "tactile space". 


\subsubsection{Organic Farmers' Market}

The organic farmers' market in Zhengzhou, initiated by the Henan Returned Youth Mutual Aid Group in 2015, is an interactive platform for local ecological agricultural producers, consumers, and sellers in Henan. The purpose is to promote the exchange and cooperation between returned youth, promote the development of farmers' market in Zhengzhou, and promote the benign operation of PGS practice and urban-rural interaction platform. After its establishment, the markets are organized regularly. In the market, there are not only the sale of organic agricultural products, but also some on-site production and experience activities, which attract the active participation of consumers who come to shopping. At the same time, there also are seminars and exchanges for green products and green life, but online interaction is less. Farmers' market is a comprehensive platform integrating shopping, experience and communication and an offline "tactile space".

Table 1 Individual characteristics of sample consumers

\begin{tabular}{|c|c|c|}
\hline Characteristic & Classification & Ratio / \% \\
\hline \multirow{2}{*}{ Gender } & Female & 80.7 \\
\hline & Male & 19.3 \\
\hline \multirow{5}{*}{ Age } & $18-24$ & 2.1 \\
\hline & $25-34$ & 22.1 \\
\hline & $36-45$ & 43.6 \\
\hline & $46-55$ & 26.1 \\
\hline & $\geq 56$ & 6.1 \\
\hline \multirow{2}{*}{ Education background } & College degree and above & 93.2 \\
\hline & Below college degree & 6.8 \\
\hline \multirow{4}{*}{ Scale of family } & 1 & 2.1 \\
\hline & 2 & 8.6 \\
\hline & 3 & 58.6 \\
\hline & $\geq 4$ & 30.7 \\
\hline \multirow{5}{*}{$\begin{array}{l}\text { Annual income of family } \\
\qquad(10000 \mathrm{RMB})\end{array}$} & $\leq 8$ & 0 \\
\hline & $8-15$ & 17.5 \\
\hline & $16-30$ & 45.7 \\
\hline & $31-80$ & 28.2 \\
\hline & $\geq 80$ & 8.6 \\
\hline
\end{tabular}

Tab. 1 shows the sociological and demographic characteristics of the sample consumers. The preliminary data analysis shows that the consumers who participate in AFN in Zhengzhou have the following characteristics: 1 . The ratio of women is much higher than that of men. 2 . Young and middle-aged people are the main body. 3. Most of them have received higher education. 4. Middle income class is the main body. These prove that at present, AFN participants are mainly from middle-income families.

The structure of the questionnaire is based on the previous theoretical framework and research hypothesis. Satisfaction, perceived quality, attitude towards AFN and participation in AFN activities were measured by Likert scale. Respondents ranked the importance of items, which were designed according to literature as green consumption and sustainable consumption $[29,30]$. The first part of the questionnaire, content and item design, drawing on Archer et al. [25], is used to capture consumers' personal characteristics and consumption habits that may be related to AFN. The second and third parts reflect the two latent variables of perceived quality and AFN product quality, and try to get feedback about the extrinsic attributes of products such as freshness, safety, and taste, and the intrinsic attributes such as origin, environmental protection, and nutritional value from the respondents. This study measures the two latent variables through these two kinds of attributes, and the item design draws lessons from Hansen [23].

\subsection{Quantitative Analysis Method}

In this study, a hypothesis model constructed to study how the attitude towards AFN, perceived quality and participation in AFN activities affect consumer satisfaction. Structural equation model (SEM) can reflect the observed latent variables by some directly observable variables, and simultaneously process multiple dependent variables to estimate the relationship between factor and factor structure, and allow certain measurement error. Therefore, this study uses structural equation model for analysis, and the measurement equation and structural equation are as follows.

Measurement Equation:

$$
\begin{aligned}
& x=A_{x} \xi+\delta \\
& y=A_{y} \eta+\varepsilon
\end{aligned}
$$

Structural Equation:

$\eta=B \eta+\Gamma \xi+\zeta$

In structural Eq. (3), $B \eta$ describes the interaction between endogenous variables $\eta . \Gamma \xi$ describes the influence of exogenous latent variable $\xi$ on endogenous latent variable $\eta$. $\zeta$ represents residual item. In the measurement equation, Eq. (1) represents the measurement equation of exogenous latent variables, and Eq. (2) represents the measurement equation of endogenous latent variables. In the structural equation model, endogenous latent variable $\eta$ includes perceived quality, participation in AFN activities and satisfaction, while exogenous latent variable $\xi$ refers to attitude towards AFN.

Firstly, confirmatory factor analysis (CFA) is used to evaluate whether the latent variables are well measured by the measurement equation, that is, whether the item design can reflect the latent variables well. For confirmatory factor analysis of the measurement model, the maximum likelihood estimate method is used to identify five latent constructs. Standard factor loading $(\lambda)$, reliability (Cronbach's $\alpha$ ), average variance extracted $(A V E)$, and basic descriptive statistical analysis results of each potential factor are shown in Tab. 2.

The Cronbach's $\alpha$ coefficient of each construct exceeds 0.7 , indicating that the scale has reliable reliability. The average variance extracted $(A V E)$ of each construct exceeds 0.5 or is very close to 0.5 , indicating that the data had high validity. The results of confirmatory factor analysis show that the measurement equation and guidance are effective and reliable. In this way, structural equation model can be used to test the research hypothesis. 


\begin{tabular}{|c|c|c|c|c|c|c|}
\hline Construct and item design & Sign & Average value & Standard Deviation & $\lambda$ & $\alpha$ & $A V E$ \\
\hline Attitude towards AFN & ATAFN & & & & 0.73 & 0.54 \\
\hline Importance of local production & ATAFN1 & 3.56 & 0.92 & 0.78 & & \\
\hline Importance of food safety & ATAFN2 & 4.54 & 0.96 & 0.86 & & \\
\hline Frequency of purchasing local food & ATAFN3 & 2.85 & 1.12 & 0.48 & & \\
\hline Perceived quality & PQ & & & & 0.78 & 0.43 \\
\hline Expected overall quality & PQ1 & 4.28 & 0.85 & 0.63 & & \\
\hline Importance of taste & PQ2 & 4.17 & 0.92 & 0.63 & & \\
\hline Importance of organic production method & PQ3 & 4.02 & 1.24 & 0.58 & & \\
\hline Participation in AFN activity & TAFN & & & & 0.86 & 0.52 \\
\hline Participation in AFN's online communication & TAFN1 & 3.67 & 0.13 & 0.69 & & \\
\hline Participation in AFN's offline experience & TAFN2 & 4.04 & 0.57 & 0.78 & & \\
\hline Participation in AFN's offline communication & TAFN3 & 2.48 & 0.12 & 0.72 & & \\
\hline Satisfaction & SAT & & & & 0.89 & 0.56 \\
\hline Overall quality & SAT1 & 4.46 & 0.70 & 0.74 & & \\
\hline Taste & SAT2 & 4.62 & 0.72 & 0.73 & & \\
\hline Organic production method & SAT3 & 4.18 & 0.86 & 0.72 & & \\
\hline Local production & SAT4 & 4.08 & 0.65 & 0.68 & & \\
\hline Freshness of food & SAT5 & 4.59 & 0.66 & 0.69 & & \\
\hline Degree of environmental impact & SAT6 & 3.82 & 0.88 & 0.80 & & \\
\hline
\end{tabular}

\section{RESULTS AND POLICY IMPLICATIONS}

The goodness of fit of the model is tested by LISEREL9.1. The results are shown in Tab. 3. The results show that the model has a good fit with the data, which shows that the test of the hypothesis is feasible.

Table 3 Evaluation indication system and fitting results of overall fitness of structural equation

\begin{tabular}{|c|c|c|c|c|}
\hline \multicolumn{2}{|c|}{ Name of index } & $\begin{array}{c}\text { Evaluation } \\
\text { standard }\end{array}$ & $\begin{array}{c}\text { Fitness } \\
\text { value }\end{array}$ & Result \\
\hline \multirow{4}{*}{ Absolute fit index } & $\chi^{2} / \mathrm{d} f$ & $>0.9$ & $390.562 / 67$ & Acceptable \\
\cline { 2 - 5 } & GFI & $>0.9$ & 0.943 & Ideal \\
\cline { 2 - 5 } & RMSEA & $<0.08$ & 0.052 & Ideal \\
\cline { 2 - 5 } & NFI & $>0.9$ & 0.904 & Ideal \\
\cline { 2 - 5 } & IFI & $>0.9$ & 0.926 & Ideal \\
\hline \multirow{3}{*}{$\begin{array}{c}\text { Comparative fit } \\
\text { index }\end{array}$} & TLI & $>0.9$ & 0.908 & Ideal \\
\cline { 2 - 5 } & CFI & $>0.9$ & 0.915 & Ideal \\
\cline { 2 - 5 } & AIC & $\begin{array}{c}\text { the smaller } \\
\text { the better }\end{array}$ & 657.841 & Ideal \\
\hline Information index & PNFI & $>0.5$ & 0.636 & Ideal \\
\cline { 2 - 5 } & PCFI & $>0.5$ & 0.680 & Ideal \\
\hline
\end{tabular}

Tab. 4 shows the path coefficient of the model and the results of significance test.

Table 4 Estimate results of path coefficient

\begin{tabular}{|l|c|c|c|}
\hline \multicolumn{1}{|c|}{ Path relationship } & $\begin{array}{c}\text { Path } \\
\text { coefficient }\end{array}$ & $\begin{array}{c}\text { Standard } \\
\text { error }\end{array}$ & $p$ \\
\hline \multicolumn{4}{|c|}{ Direct effect } \\
\hline ATAFN $\rightarrow$ PQ & 0.72 & 0.08 & $* * *$ \\
\hline $\mathrm{PQ} \rightarrow \mathrm{SAT}$ & 0.69 & 0.12 & $* *$ \\
\hline $\mathrm{ATAFN} \rightarrow$ SAT & 0.65 & 0.13 & $* *$ \\
\hline $\mathrm{ATAFN} \rightarrow \mathrm{TAFN}$ & 0.82 & 0.15 & $* *$ \\
\hline $\mathrm{TAFN} \rightarrow \mathrm{SAT}$ & 0.86 & 0.14 & $* *$ \\
\hline \multicolumn{4}{|c|}{ Indirect effect } \\
\hline $\begin{array}{l}\text { ATAFN } \rightarrow \text { SAT } \\
(\mathrm{PQ} \text { as an intermediary) }\end{array}$ & 0.50 & 0.06 & $* *$ \\
\hline $\begin{array}{l}\text { ATAFN } \rightarrow \text { SAT } \\
(\mathrm{TAFN} \text { as an intermediary) }\end{array}$ & 0.71 & 0.15 & $*$ \\
\hline
\end{tabular}

Note: $* * *$ indicates that the significance level is less than 0.01 , ** indicates that the significance level is less than $0.05, *$ indicates that the significance level is less than 0.1 .

It can be seen from Tab. 4 that the attitude towards AFN has a significant direct positive effect on perceived quality, satisfaction and participation in AFN activities, and the path coefficients are $0.72,0.65$ and 0.82 respectively, which verifies the hypotheses $\mathrm{H} 1, \mathrm{H} 3$ and $\mathrm{H} 4$. Perceived quality and participation in AFN activities have significant direct positive effects on satisfaction, and the path coefficients are 0.69 and 0.86 , respectively, verifying the hypotheses $\mathrm{H} 2$ and $\mathrm{H} 5$, indicating that participation in AFN activities has an important impact on satisfaction, and even exceeds the importance of perceived quality. From the empirical results, consumer satisfaction is indirectly affected by the attitude towards AFN through perceived quality and participation in AFN activities, with the intensity of 0.50 and 0.71 respectively, indicating that the indirect effects of these two channels cannot be ignored.

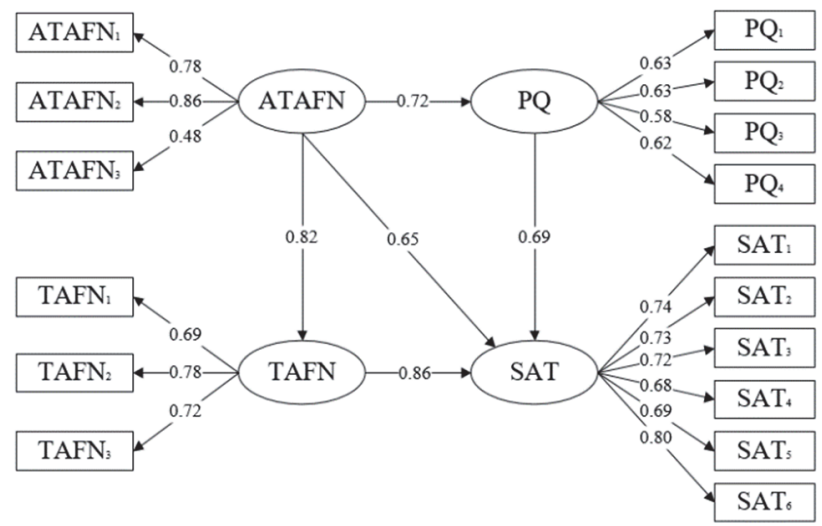

Figure 2 Path analysis of the mode

Fig. 2 shows a panoramic view of the causal relationships, paths, constructs and indications assumed in this study. The empirical study shows that the attitude towards AFN has a complex impact on consumer satisfaction through direct and indirect ways. Since green product is a kind of trust product, attitude can directly affect satisfaction, that is, consumers are satisfied because they believe in it, or they are not satisfied because they do not believe in it. For the same reason, attitude can affect the satisfaction indirectly by affecting the perceived quality of consumers and the participation in AFN activities.

Compared with the existing research, the contribution of this study lies in the following: according to the actual situation in China, this study introduces the intermediary variable of consumers' participation in AFN activities, analyzes, and empirically verifies how consumers' attitudes towards AFN affect their satisfaction with green products through direct and indirect effects. The results show that: 
consumers' attitudes towards AFN have a direct impact on their satisfaction and at the same time, through the two intermediary variables of perceived quality and participation in AFN activities, they have an indirect impact on consumer satisfaction. These effects have passed the empirical test, which are statistically significant, consistent with the theoretical hypotheses.

\section{CONCLUSIONS}

Based on the above conclusion, consumer satisfaction with AFN can improve and increase its attractiveness through the following ways: (1) Improve consumers' attitudes towards AFN. Many consumers think that AFN products have not passed the commercial certification, so it is difficult to define whether they are real green products. Besides, the price is much higher than that of ordinary products in the market, and the variety is single. To eliminate this doubt, the following measures can be taken. A). Implement and carry out the participatory guarantee system (PGS). Local consumer representatives, producer representatives, non-governmental organizations and other stakeholders form a participatory guarantee system to provide low-cost certification and services to smallholders to improve consumers' trust in AFN products. B). Communicate with consumers more. Let more consumers experience AFN, and gradually make them accept the concept of eating in the current season and not planting out of season vegetables. (2) Improve the perceived quality of AFN products. Compared with the agricultural products in the mainstream food network market, the appearance of AFN product is poorer, which is related to the production mode of AFN and the concept of AFN producers. It is necessary for AFN producers to learn from the mainstream food network and pay attention to the advantages of product appearance, to improve the perceived quality of AFN products. (3) Improve consumers' participation in AFN activities. Participating in AFN activities allows consumers to understand the production process of AFN, and it will be easier for them to accept the concept of AFN. Empirical research has proved that more participation in AFN activities can improve consumer satisfaction. AFN can learn from the practices of farmers in the mainstream food network, commercial means and methods used, to pay more attention to and meet the needs of consumers, creating online and offline parallel "tactile space" of AFN so that consumers can experience, understand, learn and communicate more, and form a "food community", so as to enhance the attractiveness of AFN to consumers.

\section{Acknowledgment}

The work is supported by The National Social Science Fund of China, Key Project (16AJL009).

\section{REFERENCES}

[1] Polanyi, K., Moiseev, N. A., Von Gadow, K., \& Krott, M. (2015). The Great Transformation: the Political and Economic Origins of Our Time. Proceedings of the National Academy of Sciences, 104(14).
[2] Yan, S., Cunwang, C., Peng, L., Yi, Z., Yang, J., \& Tiejun, W. (2011). Correlation analysis between the development of ecological urban agriculture and the rise of urban middleincome groups - based on the participatory study of the operation of "Little Donkey Farm" Community Supported Agriculture (CSA). Guizhou Social Sciences, 2011(2).

[3] Zhenzhong, S., Ning, D., \& Shudan, Q. (2018). An Overview of Critical Issues of Alternative Food Networks in the Global Context. China Agricultural University Journal of Social Science Edition, 2018(4).

[4] Fei, L. (2012). Institutional Embeddedness and Local Food System: Based on A Case Study of Three Typical CSAs in Z City. China Agricultural University Journal of Social Science Edition, 2012(1).

[5] McMichael, P. (2009). A Food Regime Genealogy. Journal of Peasant Studies, 36(01), 139-169. https://doi.org/10.1080/03066150902820354

[6] Feenstra, G. W. (1997). Local Food Systems and Sustainable Communities. American Journal of Alternative Agriculture, 12(1). https://doi.org/10.1017/S0889189300007165

[7] Hayden, J. \& Buck, D. (2012). Doing Community Supported Agriculture: Tactile Space, Affect and Effects of Membership. Geoforum, 43(2). https://doi.org/10.1016/j.geoforum.2011.08.003

[8] Kelvin, R. (1994). Community Supported Agriculture on the Urban Fringe: Case Study and Survey. Kutztown, PA: Rodale Institute Research Center.

[9] Bo, Y. (2014). Empirical Research on the Motivations and Influencing Factors of Chinese Urban Residents Joining CSA: From the Aspect of Comparison with Western Country Consumers. China Rural Survey, 2014(2).

[10] Weiping, C., Jiao, H., \& Mengyang, L. (2011). The Development Status and Prospects of Community Supported Agriculture. Agricultural Outlook, 2011(01).

[11] Weiping, C. (2015). Build community supported agriculture (CSA) consumers' trust in producers: the role of consumer social media participation. Chinese Rural Economy, 2015(6).

[12] Si, T. \& Weiping, C.(2018). How to Build Consumers' Trust in Community Supported Agriculture - The Case of Four Seasons Share Organic Farm in Huizhou, Guangdong Province. China Agricultural University Journal of Social Science Edition, 2018(4). https://doi.org/10.5304/jafscd.2012.024.003

[13] Tiejun, W. \& Yongsheng, S. (2020). Two Great Changes at the Turn of the Century and a New Explanation of Agriculture, Countryside and Farmers. Inquiry into Economic Issues, 2020(9).

[14] Man, S. (2021). The trust-building mechanism of safe food Taking the "vegetable group" in $\mathrm{H}$ city as an example. Sociological Study, 2013(3).

[15] Chungang, Z. \& Gubo, Q. (2015). On Differential Trust on Food. Social Science of Beijing, 2015(1).

[16] Pelch, L. (1996).Factors Influencing the Decision to Join a Community Supported Agriculture (CSA) Farm. Journal of Sustainable Agriculture, 10(2). https://doi.org/10.1300/J064v10n02_11

[17] Kolodinsky, J. M. \& Pelch, L. (1997). Factors Influencing Consumer Satisfaction with a Community Agriculture Farm (CSA).Journal of Consumer Satisfaction, Dissatisfaction and Complaining Behavior, 10(3). https://doi.org/10.1300/J064v10n02_11

[18] Carzedda, M., Marangon, F., Nassivera, F., \& Troiano, S. (2018). Consumer Satisfaction in Alternative Food Networks (AFNs): Evidence from Northern Italy. Journal of Rural Studies, 2018(64). https://doi.org/10.1016/j.jurstud.2018.10.003

[19] Kannan, R. (2017).The Impact of Food Quality on Customer Satisfaction and Behavioural Intentions: a Study on Madurai Restaurant. Open Journal of Business and Management, 6(3). https://doi.org/10.15520/ijbm 
[20] Chang, S., Chou, P., \& Wen-Chien, L. (2014).Evaluation of Satisfaction and Repurchase Intention in Online Food Group-Buying, Using Taiwan as an example. British Food Journal, 116(1). https://doi.org/10.1108/bfj-03-2012-0058

[21] Aydin, S., Oezer, G., \& Arasil, O. (2005). Customer Loyalty and the Effect of Switching Costs as a Moderator Variable: a Case in the Turkish Mobile Phone Market. Marketing Intelligence \& Planning, 23(1). https://doi.org/10.1108/02634500510577492

[22] Caswell, J. A. \& Mojduszka, E. M. (1996).Using Informational Labeling to Influence the Market for Quality in Food Products. American Journal of Agricultural Economics, 78(5). https://doi.org/10.2307/1243501

[23] Hansen, T. (2005).Understanding Consumer Perception of Food Quality: the Cases of Shrimps and Cheese. British Food Journal, 107(7). https://doi.org/10.1108/00070700510606909

[24] Ajzen, I. (1991). The Theory of Planned Behavior. Organizational Behavior and Human Decision Processes, 50(2). https://doi.org/10.1016/0749-5978(91)90020-T

[25] Archer, G. P., Sánchez, J. G., Vignali, G., \& Chaillot, A. (2003). Latent Consumers' Attitude to Farmers' Markets in North West England. British Food Journal, 105(8). https://doi.org/10.1108/00070700310497264

[26] Issanchou, S. (1996). Consumer Expectations and Perceptions of Meat and Meat Product Quality. Meat Science, 43(S1). https://doi.org/10.1016/0309-1740(96)00051-4

[27] Thogersen, J., Barcellos, M. D., Perin, M. G., \& Zhou, Y. (2015). Consumer Buying Motives and Attitudes towards Organic Food in Two Emerging Markets. International Marketing Review, 32(3/4). https://doi.org/10.1108/IMR-06-2013-0123

[28] Asma, S., Abdul, G., Muhammad I., Muhammad Y., \& Naveed, A. (2015). Product Perceived Quality and Purchase Intention with Consumer Satisfaction. Global Journal of Management and Business Research, 15(01).

[29] Aertsens, J., Verbeke, W., Mondelaers, K., \& Huylenbroeck, G. V. (2009). Personal Determinants of Organic Food Consumption: a Review. British Food Journal, 111(10).

[30] Balderjahn, I., Buerke, A., Kirchgeorg, M., Peyer, M., Seegebarth, B., \& Wiedmann, K. P. (2013). Consciousness for Sustainable Consumption: Scale Development and New Insights in the Economic Dimension of Consumers' Sustainability. AMS Review, 3(4). https://doi.org/10.1007/s13162-013-0057-6

\section{Contact information:}

\section{Bo YANG}

School of Economics,

Zhengzhou University of Aeronautics, China

\section{Meng-Ting LIU}

School of Economics,

Zhengzhou University of Aeronautics, China

Guo YU

(Corresponding author)

School of Economics,

Zhengzhou University of Aeronautics, China

E-mail: gyu@zua.edu.cn 